\title{
Pengembangan Potensi Ekowisata Sungai Pekalen Atas, Desa Ranu Gedang, Kecamatan Tiris, Kabupaten Probolinggo
}

\author{
Afifah Nur Aulia \\ Jurusan Biologi, Fakultas Matematika dan IImu Pengetahuan Alam \\ Universitas Brawijaya, Malang, Indonesia

\section{Luchman Hakim 1} \\ Jurusan Biologi, Fakultas Matematika dan IImu Pengetahuan Alam \\ Universitas Brawijaya, Malang, Indonesia \\ Artikel Masuk : 14 Juni 2017 \\ Artikel Diterima : 5 Oktober 2017 \\ Tersedia Online : 29 Desember 2017
}

\begin{abstract}
Abstrak: Ekosistem sungai adalah salah satu sumber daya alam potensial yang dapat dikembangkan sebagai objek dan daya tarik ekowisata untuk menyediakan lapangan kerja bagi masyarakat sekitar dan mendorong program konservasi sungai. Penelitian ini bertujuan untuk mendeskripsikan potensi atraksi ekowisata, menyusun produk ekowisata potensial, mengevaluasi preferensi wisatawan terhadap objek dan daya tarik ekowisata, dan menyusun konsep produk ekowisata yang akan dikembangkan di sepanjang Sungai Pekalen Atas. Potensi objek diidentifikasi dan dipetakan di sepanjang koridor sungai, dan dilanjutkan dengan uji preferensi responden terhadap objek ekowisata untuk menyusun peringkat dan klasifikasi pengembangan produk ekowisata. Untuk mendapatkan produk dan menyusun klasifikasi ekowisata yang sesuai dilakukan Focus Group Discussion (FGD) dengan pemangku kepentingan. Hasil penelitian menunjukkan bahwa koridor Sungai Pekalen Atas mempunyai 26 jeram, tiga air terjun, tiga kebun, tiga gua, dan 11 jenis fauna. Terdapat objek-objek potensial yang dibagi menjadi objek rafting dan non-rafting. Persepsi wisatawan terhadap produk ekowisata non-rafting yang ditawarkan adalah "menarik", sehingga objek-objek tersebut perlu dikembangkan lebih lanjut dengan mengikuti prinsip-prinsip pemanfaatan sumber daya alam berkelanjutan. Dari hasil FGD didapatkan tiga tipe produk ekowisata yang dapat dikembangkan di sepanjang Sungai Pekalen Atas yaitu low, medium dan hard level product.
\end{abstract}

Kata kunci: ekowisata, konservasi, pemetaan potensi, pengembangan produk

Abstract: River ecosystem is a potential resource for ecotourism development necessary to job creation for the local community and river conservation support. The aims of this research are to depict the ecotourism attraction potentials, to prepare ecotourism product designs, to evaluate tourist's preferences regarding ecotourism objects and attractions, and to develop a typology of tourism products prospectively developed along the Pekalen Atas

\footnotetext{
Korespondensi Penulis: Jurusan Biologi, Fakultas Matematika dan Ilmu Pengetahuan Alam

Universitas Brawijaya, Malang, Indonesia

Email: luchman@ub.ac.id
} 


\section{Pengembangan Potensi Ekowisata Sungai Pekalen Atas...}

River. This study was completed from October 2016 to March 2017 in Pekalen Atas River, Ranu Gedang Village, Tiris Subdistrict, Probolinggo Regency. This research covered object identification and mapping steps along the riverbank, and then followed by respondent preferences testing toward the ecotourism objects required to the making of ecotourism product development's classification and ranking. This product was also developed by taking stakeholders' feedback into account during the Focus Group Discussion (FGD). The result reveals that the Pekalen Atas Riverbank consists of 26 rapids, three waterfalls, three fields, three caves and 11 animal species. The potential objects could be classified into rafting and non-rafting. Based on tourists' perceptions, the non-rafting objects are considered "attractive" so that their further developments should meet the principles of sustainable natural resources utilization compliance. The FGD results confirmed three types of ecotourism products that could be developed along the Pekalen Atas Riverbank, i.e. low-, medium-and hard-level product.

Keywords: conservation, ecotourism, product development, tourism resources mapping

\section{Pendahuluan}

Sungai adalah salah satu ekosistem yang secara potensial dapat dikembangkan sebagai objek dan daya tarik wisata, terutama dalam kegiatan arung jeram atau rafting (Arnould \& Price, 1993; Prideaux \& Cooper, 2009). Pengembangan ekosistem sungai sebagai objek dan daya tarik tersebut relevan dengan kecenderungan pertumbuhan dan kinerja sektor wisata di Indonesia, khususnya wisata alam dan ekowisata. Pada tahun 2010 perolehan angka devisa dari pariwisata mencapai 7,6 juta USD, tahun 2011 meningkat menjadi 8,5 juta USD, dan tahun 2012 meningkat kembali menjadi 9,1 juta USD. Pada tahun 2013 kontribusi ekonomi pariwisata mencapai 10,1 juta USD, dan tahun 2014 mencapai 11,2 juta USD. Diharapkan di masa mendatang sektor wisata dapat menggantikan penerimaan negara dari industri minyak dan gas bumi, minyak kelapa sawit, dan batubara, serta karet olahan (Kementerian Pariwisata Republik Indonesia, 2016).

Sungai Pekalen di Kabupaten Probolinggo adalah sumber daya alam yang saat ini telah dimanfaatkan sebagai atraksi wisata arung jeram. Sungai Pekalen terbagi atas tiga area yaitu Sungai Pekalen Atas (panjang $12 \mathrm{~km}$ ), Sungai Pekalen Tengah (panjang $7 \mathrm{~km}$ ), dan Sungai Pekalen Bawah (panjang $10 \mathrm{~km}$ ). Sungai Pekalen digunakan sebagai wisata arung jeram karena arusnya yang cukup deras, banyaknya jeram di sepanjang sungai, dan juga kawasan sekitarnya yang masih alami. Hal tersebut membuat wisata arung jeram di Sungai Pekalen banyak diminati oleh masyarakat. Saat ini terdapat tiga operator yang memanfaatkan Sungai Pekalen sebagai lokasi wisata arung jeram yaitu, Noars Rafting, Songa Rafting dan Regulo Rafting. Data statistik menunjukkan bahwa terjadi peningkatan jumlah kunjungan wisatawan dengan jumlah kunjungan wisatawan berkisar antara 200-500 orang tiap bulannya (Songa, 2016).

Adanya pemanfaatan sungai yang intensif dan masif dalam kegiatan rafting dikhawatirkan akan memberikan dampak terhadap ekosistem sungai. Pemanfaatan di luar kemampuan ekosistem sungai dalam menerima kunjungan akan berdampak terhadap degradasi sungai. Secara sosial, pemanfaatan alur sungai secara intensif juga berdampak pada kenyamanan masyarakat lokal dalam memanfaatkan sungai untuk mendukung kehidupan sehari-hari. Sampai saat ini, upaya pengembangan wisata non-arung jeram untuk mengurangi beban sungai dari kegiatan arung jeram belum dilakukan karena keterbatasan data dan informasi. Wisata non-arung jeram adalah wisata selain penelurusan arung jeram sepanjang sungai, antara lain: pengamatan flora-fauna, penelusuran potensi permukiman dan kebun masyarakat, atau bentuk wisata edukasi lainnya yang dilakukan di sepanjang aliran sungai (Prideaux \& Cooper, 2009; Steinbach, 1995). Diversifikasi produk wisata adalah salah satu kunci dalam menjaga keseimbangan pemanfaatan seluruh sumber daya potensial menuju destinasi wisata yang berkelanjutan. Dalam konteks Sungai Pekalen 
Atas diperlukan sebuah upaya pengembangan diversifikasi produk wisata non-arung jeram untuk mengurangi beban sungai dari kegiatan wisata arung jeram guna menjamin keberlanjutan fungsi dari ekosistem sungai (Postel \& Richter, 2012; Prideaux \& Cooper, 2009; Zhu, Drake, Lü, \& Xia, 2010). Langkah strategis dalam pengembangan sungai adalah dengan mengoptimalkan potensi di sekitar sungai sebagai objek dan daya tarik wisata alternatif. Sejauh ini, belum ada kajian untuk memetakan potensi ekosistem sungai sebagai pijakan dalam pengembangan wisata Sungai Pekalen Atas lebih lanjut. Oleh karena itu, penelitian ini bertujuan untuk mengetahui potensi sungai, mengembangkan produk ekowisata potensial non-arung jeram sepanjang Sungai Pekalen Atas, mengetahui preferensi wisatawan terhadap objek dan daya tarik ekowisata alternatif sepanjang Sungai Pekalen Atas dan menyusun tipe kegiatan ekowisata yang dapat dikembangkan di sepanjang Sungai Pekalen Atas.

\section{Metode Penelitian}

\section{Deskripsi Area Studi}

Penelitian ini dilaksanakan di Sungai Pekalen Atas, Desa Ranu Gedang, Kecamatan Tiris, Kabupaten Probolinggo. Sungai Pekalen adalah jalur wisata arung jeram yang banyak dikunjungi wisatawan di Jawa Timur. Bantaran sungai yang bisa diarungi berjarak $29 \mathrm{~km}$ yang terbagi atas tiga area yaitu Sungai Pekalen Atas berjarak $12 \mathrm{~km}$, Sungai Pekalen Tengah berjarak $7 \mathrm{~km}$, dan Sungai Pekalen Bawah berjarak $10 \mathrm{~km}$. Sungai Pekalen merupakan sungai permanen dan dapat digunakan sebagai wahana arung jeram sepanjang tahun (Songa, 2016). Tahapan kerja dan analisis penelitian ini dapat dilihat pada Gambar 1.

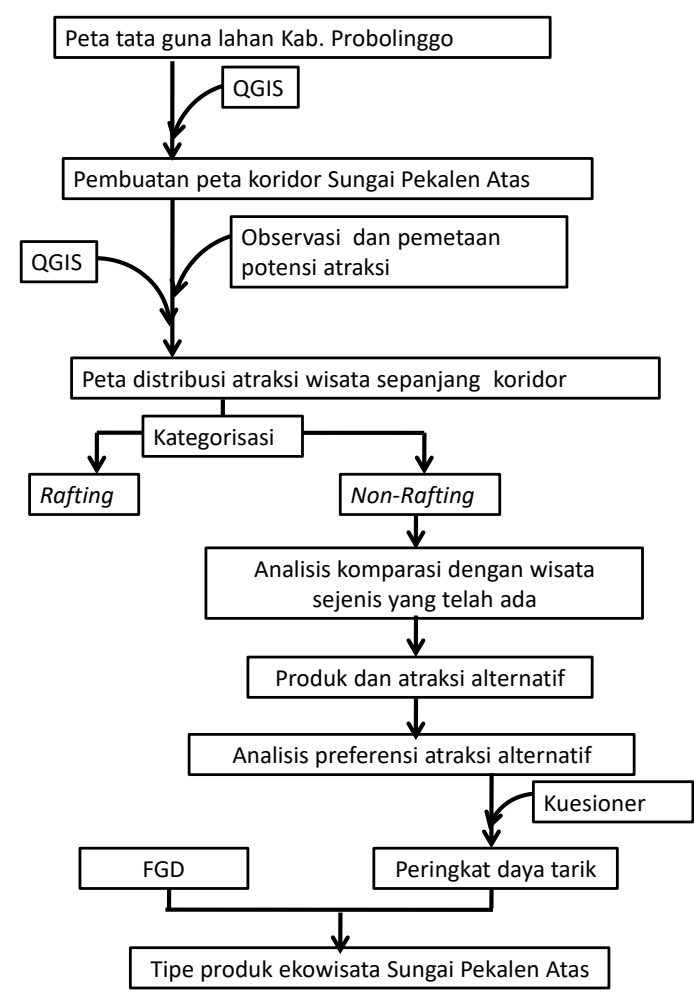

Sumber: Analisis Penyusun, 2016 


\section{Pembuatan Peta Koridor dan Observasi Potensi Sungai}

Pembuatan peta koridor ini bertujuan untuk mengetahui basis data peta untuk input dan pengolahan data spasial distribusi objek wisata potensial sepanjang sungai dan zona riparian di sekitarnya. Peta dibuat dengan menggunakan software QGIS untuk memperoleh peta aliran Sungai Pekalen Atas dengan buffer $100 \mathrm{~m}$ ke kanan maupun ke kiri dari bibir sungai mulai dari start point sampai finish dari kegiatan wisata arung jeram di Sungai Pekalen Atas.

Pengamatan potensi dilakukan di sepanjang sungai dengan menggunakan metode inventarisasi potensi atraksi sepanjang alur sungai (Hauer \& Lamberti, 2011). Fokus pengamatan adalah pada objek-objek yang mempunyai potensi keunikan dan daya tarik wisata sepanjang alur sungai. Setiap tempat dan objek potensial yang dijumpai dicatat, didokumentasikan dan dipetakan koordinat geografisnya dengan menggunakan GPS. Jenis flora dan fauna yang ditemukan dicatat pada tabel pengamatan. Data koordinat objek potensial, jenis flora dan fauna dianalisis dengan software QGIS untuk menghasilkan peta distribusi potensi ekowisata sepanjang Sungai Pekalen Atas (Ritchie, Burns, \& Palmer, 2005).

\section{Pengembangan dan Evaluasi Produk Non-Rafting}

Potensi objek sepanjang sungai diidentifikasi dan dianalis untuk mendapatkan data spot-spot potensial dan atraksi ekowisata yang akan dikembangkan sebagai objek dan produk ekowisata non-arung jeram. Produk-produk potensial dikembangkan dengan cara melakukan komparasi dengan produk sejenis yang telah ada di berbagai destinasi wisata lewat penelusuran pustaka, analisis brosur wisata, tourism guide book dan material program wisata lainnya. Objek dan produk alternatif yang dihasilkan selanjutnya diuji melalui analisis preferensi persepsi wisatawan terhadap objek dan produk ekowisata melalui kuesioner sehingga didapatkan peringkat dari masing-masing objek dan produk. Kuesioner didistribusikan kepada 96 responden secara sengaja (purposive sampling) dengan kriteria responden yaitu: (1) pria atau wanita, (2) berusia 18-60 tahun, (3) pernah melakukan wisata arung jeram di Sungai Pekalen Atas. Dasar dari penentuan responden mengikuti metode penentuan responden untuk wisata yang disarankan oleh Ritchie, Burns, \& Palmer (2005).

\section{Focus Group Discussion (FGD)}

Hasil dari penyusunan produk alternatif ekowisata non-arung jeram Sungai Pekalen Atas dievaluasi dan diverifikasi melalui kegiatan Focus Group Discussion (FGD). FGD dilakukan untuk membahas potensi ekowisata yang telah diidentifikasi dan merumuskan tipe ekowisata yang dapat dikembangkan lebih lanjut. Tipe ekowisata adalah bentuk dan kegiatan ekowisata yang dihasilkan dari penggolongan dan klasifikasi jenis-jenis ekowisata yang mempunyai hubungan dengan aktivitas, kesiapan fisik wisatawan, dan tingkat risiko yang berbeda dalam pelaksanaannya. FGD dilakukan dengan mengundang 10 peserta yang terdiri dari biro perjalanan wisata, ahli ekowisata, dan kelompok pemerhati ekowisata di Jawa Timur yang tergabung dalam East Java Ecotourism Forum. Syarat peserta FGD adalah memahami wisata alam, pernah terlibat dalam kegiatan arung jeram baik sebagai wisatawan, pemandu wisata, perencana perjalanan dari biro perjalanan dan pakar kepariwisataan. Mekanisme dari FGD tersebut meliputi pembukaan dan penjelasan maksud dari diskusi, perkenalan, menjelaskan prosedur pertemuan, paparan rencana pengembangan produk, diskusi pembahasan, kesimpulan, dan penutup. Fokus dan materi yang menjadi bahan diskusi adalah melakukan analisis potensi wisata yang didapatkan di sepanjang Sungai Pekalen Atas secara komprehensif dan merumuskan tipe wisata yang 
tepat sesuai potensi yang didapatkan berdasarkan pengetahuan, keahlian dan pengalaman peserta diskusi.

\section{Analisis Data}

Data hasil koordinat yang sudah didapat dari observasi dianalisis dengan menggunakan software QGIS. Data pendataan berupa titik titik koordinat potensial diakumulasikan dengan menggunakan Microsoft Excel. Data hasil FGD dianalisis dengan pengambilan kesimpulan dari permasalahan yang diajukan. Data hasil kuesioner dianalisis dan diakumulasikan dengan menggunakan analisis berupa grafik persentase dan Skala Likert dengan rumus sebagai berikut (Hakim, 2014):

$$
A i=\frac{(a \times 5)+(b \times 4)+(c \times 3)+(d x 2)+(e x 1)}{a+b+c+d+e}
$$

Keterangan:

$\mathrm{Ai}=$ persepsi untuk butir pertanyaan yang ke-i

$\mathrm{a}=$ jumlah respon yang memiliki jawaban a

$\mathrm{b}=$ jumlah respon yang memiliki jawaban $\mathrm{b}$

$\mathrm{c}=$ jumlah respon yang memiliki jawaban $\mathrm{c}$

$\mathrm{d}=$ jumlah respon yang memiliki jawaban $\mathrm{d}$

$\mathrm{e}=$ jumlah respon yang memiliki jawaban $\mathrm{e}$

Nilai-nilai dari perhitungan tersebut akan masuk dalam salah satu kategori sebagai berikut: $1<x<1,8$ (sangat tidak setuju), 1,81<x<2,6 (tidak setuju), 2,6<x<3,4 (netral), $3,41<x<4,2$ (setuju), dan $4,21<x<5$ (sangat setuju).

\section{Hasil Pembahasan}

\section{Peta Potensi Atraksi Sungai Pekalen}

Berdasarkan hasil penelitian, Sungai Pekalen Atas mempunyai atraksi potensial berupa jeram, air terjun, gua, flora dan fauna. Secara spasial, distribusi jeram ditunjukkan pada Gambar 2. Sepanjang aliran Sungai Pekalen Atas terdapat 26 jeram antara lain Jeram Selamat Datang 1, Jeram Selamat Datang 2, Jeram Bajing Loncat, Jeram Genggong, Jeram Fly Matador, Jeram Air Terjun Angin-Angin, Jeram Hiu, Jeram Batu Dodol, Jeram Good Bye, Jeram Indosat, Jeram Jumping, Jeram Lumba-Lumba, Jeram S, Jeram Kuda Nil, Jeram Panjang, Jeram Tangga Dewa, Jeram Titanic, Jeram B, Jeram Jenggot, Jeram Inul, Jeram Grojokan, Jeram Kuda Liar, Jeram KPLA, Jeram Pilar, Jeram Rajawali dan Jeram Stress. Kepadatan jeram per $\mathrm{km}$ adalah 2.16 jeram $/ \mathrm{km}$. Hal ini termasuk ideal dalam aktivitas wisata arung jeram. Wisata arung jeram sampai saat ini adalah salah satu wisata air yang menarik, dan dapat dikembangkan pada sungai sungai dengan jeram yang dimilikinya (Prideaux \& Cooper, 2009).

Sepanjang Sungai Pekalen Atas juga terdapat tiga air terjun, yaitu air terjun AnginAngin, air terjun Semilir Angin dan air terjun Tangga Dewa. Namun demikian, keberadaan air terjun tersebut sedikit mendapat perhatian dari wisatawan dan operator wisata arung jeram. Rendahnya perhatian ini disebabkan karena wisatawan dan operator wisata lebih fokus menikmati sensasi bermain di jeram-jeram yang ada sepanjang sungai dan tidak adanya waktu yang disediakan oleh operator arung jeram untuk berhenti sesaat menikmati air terjun tersebut. Selain potensi sebagai objek dan daya tarik yang dapat dikembangkan, secara ekologi, keberadaan air terjun penting dalam menyediakan air pada aliran Sungai 
Pekalen. Air terjun adalah ekosistem penting dari sungai yang berpotensi sebagai objek wisata (Gong, Ma, Tian, \& Chen, 2009; Prasetyo, Hakim, \& Retnaningdyah, 2017)

Sepanjang aliran sungai juga merupakan habitat dan titik dengan kekayaan satwa yang melimpah, meliputi Gua Kelelawar yang merupakan habitat kelelawar, Gua Ular, habitat monyet, dan habitat burung. Beberapa burung yang tercatat pada saat penelitian adalah Cekakak Sungai (Todirhamphus chloris), Kutilang (Pycnonotus aurigaster), Kacamata (Zosterops palpebrosus), Madu Jawa (Acthopyga mystacalis), Perenjak (Prinia familiaris), Walet (Collocalia vestita), dan Bondol Peking (Lonchura punctulata). Namun demikian, diduga bahwa jenis dan jumlahnya dapat melimpah. Hal ini karena Sungai Pekalen masuk dalam zona sekitar area konservasi dengan tingkat kekayaan burung yang tinggi di Jawa Timur (Whitten, Soeriaatmadja, \& Afiff, 1996). Hal ini menunjukkan bahwa Sungai Pekalen Atas adalah habitat penting bagi keanekaragaman hayati, dan perlu mendapat perhatian dalam aspek konservasi dan pengembangan pariwisata berkelanjutan (Brightsmith, Stronza, \& Holle, 2008; Burger, 2000; Hunter, 1997).

Terdapat dua ekosistem perkebunan yang potensial untuk dikembangkan sebagai lokasi wisata non-arung jeram, yaitu kebun alpukat dan kebun pisang yang dikelola oleh warga. Pada saat pengamatan didapatkan pohon alpukat dan pisang berbuah lebat, mengindikasikan produktivitas yang tinggi dari kebun. Keberadaan dua jenis tanaman ini dapat menjadi indikasi bagi pengembangan agrowisata potensial di sepanjang Sungai Pekalen. Pengembangan agrowisata saat ini menjadi salah satu fokus dari berbagai kawasan lewat optimalisasi produk-produk pertanian yang ada (Gao, Barbieri, \& Valdivia, 2014; Kizos \& Iosifides, 2007; Prasetyo et al., 2017). Sungai Pekalen Atas mempunyai potensi pengembangan ekowisata yang dapat memberikan kontribusi positif bagi petani dan masyarakat sekitar Sungai Pekalen Atas yang saat ini kurang terlibat dalam wisata arung jeram.

\section{Pengembangan Produk Ekowisata Potensial Non-Rafting}

Hasil identifikasi objek potensial yang dipilih dengan cara membandingkan dengan produk sejenis atau produk yang telah ada sebelumnya (lihat Tabel 1).

Tabel 1. Potensi Objek Sebagai Atraksi Ekowisata (Non-Arung Jeram)

\begin{tabular}{|c|c|c|c|}
\hline No & Potensi Objek & Produk Wisata & Koordinat \\
\hline 1. & Habitat Burung & Bird Watching & $07^{\circ} 54^{\prime} 57,8^{\prime \prime} \mathrm{LS}, 113^{\circ} 21^{\prime} 37,8^{\prime \prime} \mathrm{BT}$ \\
\hline 2. & Air Terjun Tangga Dewa & Air Terjun Tangga Dewa & $07^{\circ} 55^{\prime} 38,15^{\prime \prime} \mathrm{LS}, 113^{\circ} 21^{\prime} 39,78^{\prime \prime} \mathrm{BT}$ \\
\hline 3. & Kebun Alpukat & Agrowisata Alpukat & $07^{\circ} 55^{\prime} 17,2^{\prime \prime} \mathrm{LS}, 113^{\circ} 21^{\prime} 37,6^{\prime \prime} \mathrm{BT}$ \\
\hline 4. & Kebun Pisang & $\begin{array}{l}\text { Agrowisata atau } \\
\text { Arboretum Pisang }\end{array}$ & $07^{\circ} 54^{\prime} 59,5^{\prime \prime} \mathrm{LS}, 113^{\circ} 21^{\prime} 39,8^{\prime \prime} \mathrm{BT}$ \\
\hline 5 & Habitat Kelelawar* & Bat Watching & $07^{\circ} 55^{\prime} 42,25^{\prime \prime} \mathrm{LS}, 113^{\circ} 21^{\prime} 48,79^{\prime \prime} \mathrm{BT}$ \\
\hline 6 & Air Terjun * & Air Terjun Semilir Angin & $07^{\circ} 55^{\prime} 45,6^{\prime \prime} \mathrm{LS}, 113^{\circ} 22^{\prime} 1,05^{\prime \prime} \mathrm{BT}$ \\
\hline 7 & Air Terjun* & Air Terjun Angin-Angin & $07^{\circ} 55^{\prime} 40,6^{\prime \prime} \mathrm{LS}, 113^{\circ} 21^{\prime} 42,6^{\prime \prime} \mathrm{BT}$ \\
\hline 8 & Gua Kelelawar* & Gua Kelelawar & $07^{\circ} 55^{\prime} 42,25^{\prime \prime} \mathrm{LS}, 113^{\circ} 21^{\prime} 48,79^{\prime \prime} \mathrm{BT}$ \\
\hline 9 & Gua Ular* & Gua Ular & $07^{\circ} 55^{\prime} 41,31^{\prime \prime} \mathrm{LS}, 113^{\circ} 21^{\prime} 48,24^{\prime \prime} \mathrm{BT}$ \\
\hline
\end{tabular}

Sumber: Analisis Penyusun, 2017

Keterangan:

* : jenis yang terintegrasi dengan arung jeram 
Sepanjang aliran Sungai Pekalen Atas terdapat dua kategori potensi pengembangan lebih lanjut, yaitu objek dan daya tarik yang menjadi bagian dari ekosistem sungai dan objek dan daya tarik ekosistem sekitar sungai. Kategori pertama meliputi air terjun dan habitat kelelawar dan ular. Objek-objek ini berpotensi untuk dikembangkan sebagai bagian dari pengamatan satwa di habitat alamiah. Untuk meningkatkan daya tariknya diperlukan upaya lanjut dalam membuka akses ke lokasi dengan tetap mempertimbangkan keselamatan dan perlindungan satwa dan habitatnya. Potensi pengembangan berbagai satwa saat ini semakin besar, dan pada titik-titik tertentu sepanjang aliran Sungai Pekalen Atas dapat dikembangkan sebagai titik pengamatan satwa (Burns \& Howard, 2003; Reynolds \& Braithwaite, 2001; Stoeckl, Smith, Newsome, \& Lee, 2005). Kategori kedua meliputi potensi objek dan daya tarik yang tersebar pada area sekitar sungai, meliputi kebun-kebun monokultur dan kebun campuran (agroforestry) yang dapat dikembangkan sebagai wisata pengamatan burung dan agrowisata. Di berbagai kawasan, lahan-lahan pertanian monokultur dan polikultur telah dikembangkan sebagai area agrowisata yang menjadi salah satu alternatif dari kegiatan wisata utama yang telah dikenal secara luas (Barbieri \& Valdivia, 2010; Trinca, Petroman, \& Țigan, 2011).

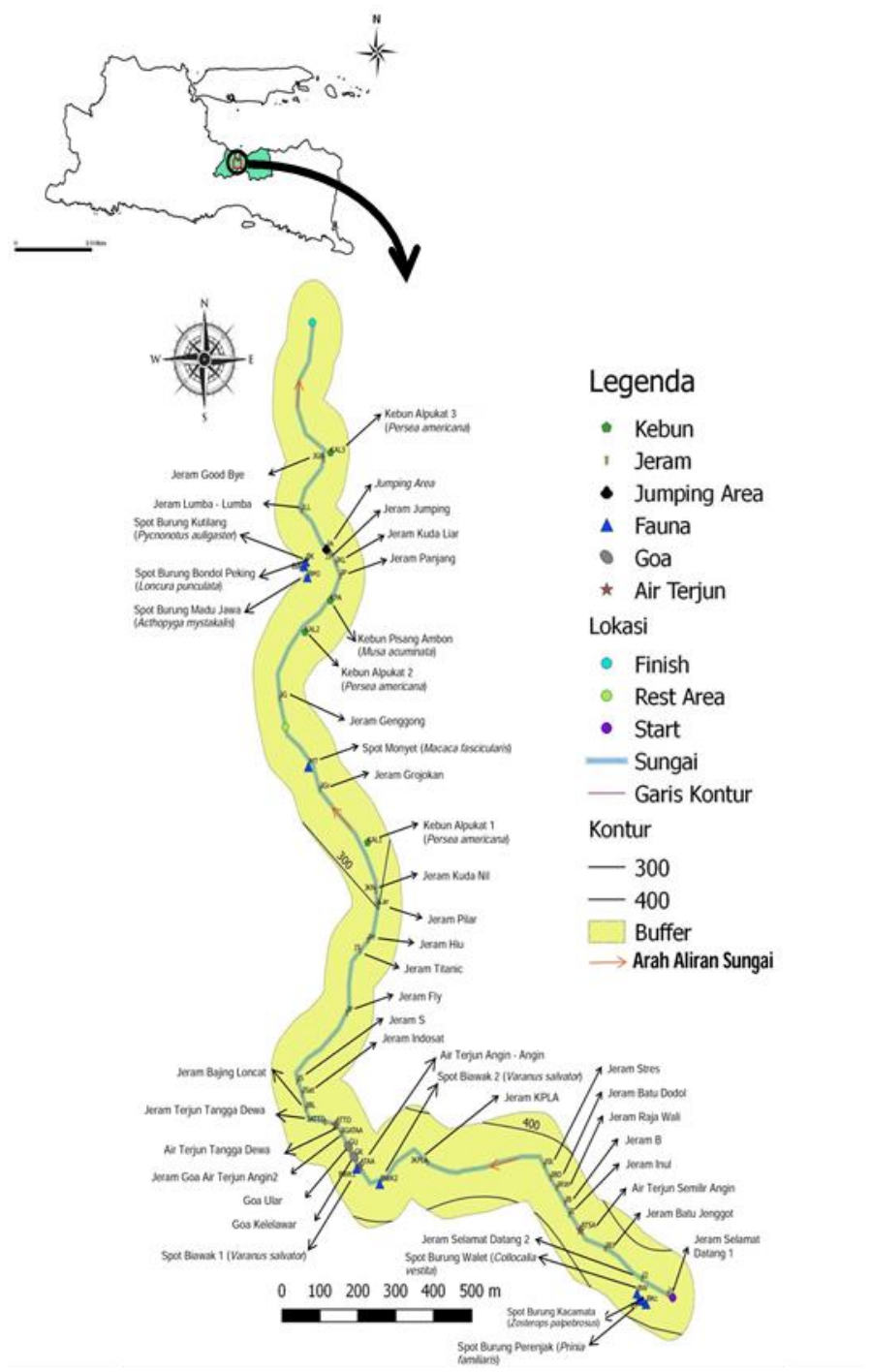

Sumber: Analisis Penyusun, 2016

Gambar 2. Distribusi Jeram dan Objek-objek Wisata Potensial Lainnya Sepanjang Sungai Pekalen Atas 
Pemetaan potensi sumber daya sepanjang Sungai Pekalen Atas dengan jelas menunjukkan distribusi potensi atraksi wisata sepanjang aliran sungai. Dalam konteks keruangan sungai, terdapat empat zona dengan konsentrasi dan kepadatan jeram atraksi wisata. Area dengan kepadatan jeram yang rendah mempunyai potensi sebagai habitat satwa dan kebun sehingga memungkinkan pada area-area tersebut dikembangkan produk wisata lainnya, seperti pengamatan satwa dan agrowisata. Pengembangan ini sangat strategis terutama untuk mengurangi konsentrasi wisatawan pada satu kegiatan wisata dan membuka peluang bagi upaya pengembangan potensi lainnya (Benur \& Bramwell, 2015; Sharpley, 2002).

\section{Preferensi Wisatawan terhadap Objek Ekowisata}

Hasil penelitian terhadap 96 responden didapatkan hasil seperti pada Gambar 3, dan nilai preferensi wisatawan pada Tabel 2 sebagai berikut.

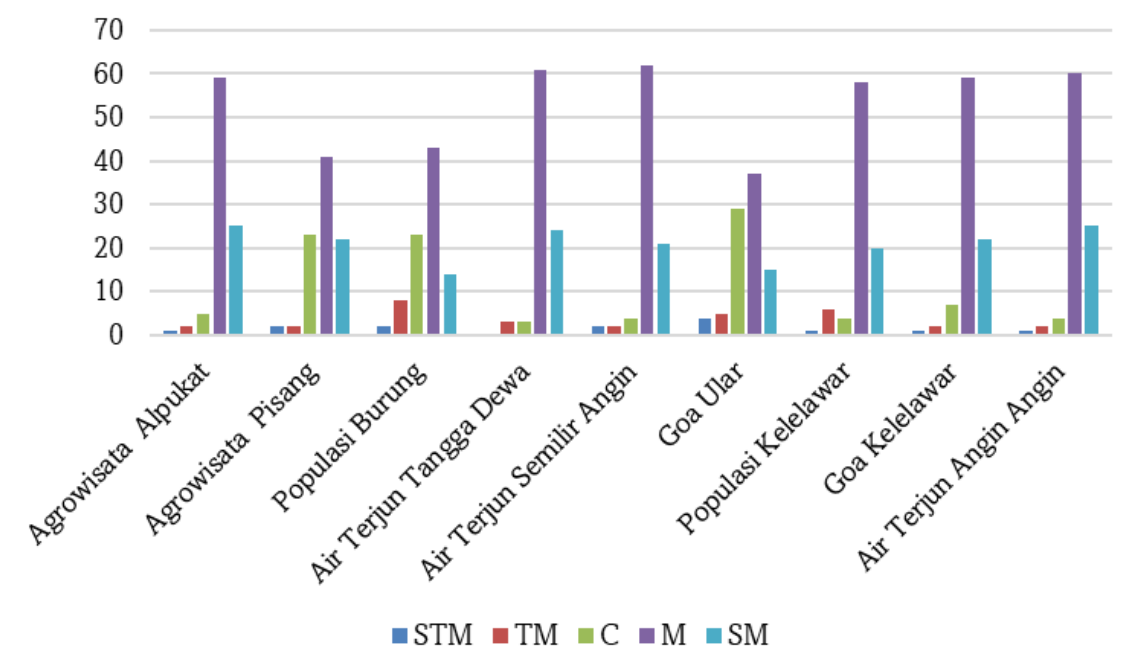

Sumber: Analisis Penyusun, 2016

\section{Gambar 3. Persentase Wisatawan terhadap Atraksi Ekowisata STM=Sangat tidak menarik, TM=Tidak menarik, C=Cukup, M=Menarik, SM=Sangat menarik)}

Tabel 2. Nilai Preferensi Wisatawan terhadap Objek Ekowisata Non-Arung Jeram

\begin{tabular}{lcc}
\hline \multicolumn{1}{c}{ Atraksi ekowisata } & Nilai & Kategori \\
\hline Air Terjun Semilir Angin & 4.3 & Sangat Menarik \\
Air Terjun Tangga Dewa & 4.3 & Sangat Menarik \\
Air Terjun Angin-Angin & 4.2 & Menarik \\
Gua Kelelawar & 4.2 & Menarik \\
Kebun dan Agrowisata Alpukat & 4.2 & Menarik \\
Kelelawar (Bat watching) & 4.1 & Menarik \\
Kebun, Agrowisata Pisang & 4.1 & Menarik \\
Gua Ular & 4.0 & Menarik \\
Burung (Bird watching) & 3.9 & Menarik \\
\hline
\end{tabular}

Sumber: Analisis Penyusun, 2017

Persentase responden yang memiliki ketertarikan terhadap potensi atraksi sejalan dengan tingkat ketertarikan responden terhadap objek. Tiga air terjun mendapat skor 
preferensi tertinggi dibandingkan objek-objek potensial lainnya. Air terjun adalah objek yang sangat potensial untuk dikembangkan. Di berbagai tempat, air terjun adalah atraksi wisata alam yang sangat digemari dan ramai dikunjungi oleh wisatawan. Air terjun sejak lama telah dikenal sebagai salah satu objek wisata alam yang menarik (Gong et al., 2009; Hudson, 1998; Prasetyo et al., 2017). Kendala bagi preferensi yang rendah dari kegiatan pengamatan satwa dibandingkan objek air terjun disebabkan oleh beberapa hal antara lain objek mudah bergerak dan sulit diamati, ukuran kecil dan jarang, serta isu keamanan wisatawan. Hal ini sesuai dengan pendapat peneliti yang menyatakan perlu adanya upaya lebih dalam mendorong popularitas wisata pengamatan satwa (Burns \& Howard, 2003; Duffus \& Dearden, 1990; Reynolds \& Braithwaite, 2001).

\section{Tipe Produk Ekowisata Sungai Pekalen Atas}

Berdasarkan rekomendasi dari FGD didapatkan tiga tipe produk yang meliputi:

1. Low level product, merupakan produk wisata dengan aktivitas ringan dan berisiko rendah, yaitu pengembangan kawasan agrowisata tanaman buah (alpukat dan pisang, serta potensi buah lainnya). Pengembangan produk ini berpotensi dikembangkan karena daya dukung lahan, terutama dalam aspek kesuburan dan kesesuaian lahan. Agrowisata saat ini adalah salah satu sektor wisata yang berkembang pesat di dunia dan mempunyai potensi untuk dikembangkan lebih lanjut untuk meningkatkan kesejahteraan masyarakat desa (Malkhanti \& Routry, 2011; Wicks \& Merrett, 2003).

2. Medium level product, merupakan produk wisata dengan aktivitas sedang, petualangan, dengan tingkat risiko yang rendah dan mengandung muatan pendidikan konservasi bagi wisatawan. Produk yang dapat dikembangkan adalah pengamatan burung (birdwatching). Dalam pengembangan kegiatan ini, perbaikan kualitas lingkungan, terutama habitat burung mutlak diperhatikan sebagai bagian dari keberhasilan produk wisata pengamatan burung. Pengamatan burung secara global adalah kegiatan wisata yang banyak mendapat respon positif dari masyarakat. Secara ekonomi, kegiatan pengamatan burung juga mendatangkan manfaat ekonomi yang penting (Cooper, Larson, Dayer, Stedman, \& Decker, 2015; Kim, Scott, Thigpen, \& Kim, 1998).

3. High level product, merupakan produk yang dikategorikan ke dalam kegiatan wisata petualangan dengan risiko tinggi, namun tetap menarik. Semua produk yang termasuk dalam level ini dapat diakses dengan cara arung jeram atau penelusuran sungai. Produk ini dapat diintegrasikan dalam kegiatan arung jeram, antara lain: pengamatan ular, kelelawar, dan air terjun sepanjang Sungai Pekalen. Dalam pelaksanaannya kategori wisata ini membutuhkan kualitas produk yang tinggi dengan tingkat kenyamanan dan keamanan yang baik (Bentley, Cater, \& Page, 2010; Bentley, Page, \& Walker, 2004).

Hasil penelitian ini menunjukkan bahwa ekowisata Sungai Pekalen Atas dapat dioptimalkan dengan cara diversifikasi produk non-rafting. Hal ini dapat dilakukan dengan mendorong area sekitar sungai untuk mengembangkan berbagai produk wisata alternatif. Melalui hal tersebut, akan didapatkan inovasi-inovasi produk ekowisata baru yang juga dapat mengurangi beban ekosistem sungai dan sekaligus membuka lapangan pekerjaan bagi masyarakat sekitar sungai yang saat ini belum terlibat dalam kegiatan wisata arung jeram (Benur \& Bramwell, 2015; Jaafar \& Maideen, 2012). Hal ini sesuai dengan prinsip ekowisata, yaitu kegiatan wisata dilakukan dengan tetap memberikan perlindungan kepada lingkungan, mempromosikan kegiatan konservasi serta memberikan dampak positif bagi masyarakat (Benur \& Bramwell, 2015; Burger, 2000; Hunter, 1997; Jaafar \& Maideen, 2012; Prasetyo et al., 2017). Dalam konteks kebijakan pemerintah Indonesia, hal ini sesuai dan 
mendukung program Sapta Pesona yang merupakan penjabaran dari Sadar Wisata untuk menciptakan Indonesia sebagai daerah tujuan wisata kelas dunia (Hamzah \& Utomo, 2016).

\section{Kesimpulan}

Sungai Pekalen Atas mempunyai objek-objek potensial yang dapat dijadikan sebagai produk wisata. Potensi tersebut antara lain adalah habitat satwa, air terjum, jeram dan ekosisitem kebun masyarakat. Objek-objek tersebut dapat dikemas dan dikelola sebagai objek wisata yang menjadi bagian dari kegiatan rafting dan non-rafting. Potensi objek wisata yang dapat diintegrasikan dalam kegiatan rafting di antaranya adalah Bat Watching, Air Terjun Semilir Angin, Air Terjun Angin-Angin, Gua Kelelawar, dan Gua Ular. Objek wisata yang dapat dikembangkan sebagai daya tarik wisata non-rafting di antaranya adalah Bird Watching, Air Terjun Tangga Dewa, Agrowisata Alpukat, Agrowisata atau Arboretum pisang. Persepsi wisatawan menunjukkan bahwa wisatawan cenderung mengatakan "menarik" pada kesembilan produk yang telah disarankan, sehingga objekobjek tersebut perlu dikembangkan lebih lanjut dengan mengikuti prinsip-prinsip pemanfaatan sumber daya alam berkelanjutan. Konsep produk yang disarankan dari hasil FGD yaitu ekowisata dengan dibagi ke dalam tiga level produk yaitu low level product, medium level product, dan hard level product.

\section{Ucapan Terima Kasih}

Terimakasih kami ucapkan kepada Manajemen Songa Adventure dan East java Ecotourism Forum (EJEF) yang telah mendukung kegiatan penelitian ini, serta Working Group Empowering Local Flora and Indigenous Landscape (ELFIL) Jurusan Biologi FMIPA Universitas Brawijaya.

\section{Daftar Pustaka}

Arnould, E. J., \& Price, L. L. (1993). River magic: Extraordinary experience and the extended service encounter. Journal of Consumer Research, 20(1), 24-45. doi: 10.1086/209331.

Barbieri, C., \& Valdivia, C. (2010). Recreation and agroforestry: Examining new dimensions of multifunctionality in family farms. Journal of Rural Studies, 26(4), 465-473. doi: 10.1016/j.jrurstud.2010.07.001.

Bentley, T. A., Cater, C., \& Page, S. J. (2010). Adventure and ecotourism safety in Queensland: Operator experiences and practice. Tourism Management, 31(5), 563-571. doi: 10.1016/j.tourman.2009.03.006.

Bentley, T. A., Page, S., \& Walker, L. (2004). The safety experience of New Zealand adventure tourism operators. Journal of Travel Medicine, 11(5), 280-286. doi: 10.2310/7060.2004.19103.

Benur, A. M., \& Bramwell, B. (2015). Tourism product development and product diversification in destinations. Tourism Management, 50, 213-224. doi: 10.1016/j.tourman.2015.02.005.

Brightsmith, D. J., Stronza, A., \& Holle, K. (2008). Ecotourism, conservation biology, and volunteer tourism: A mutually beneficial triumvirate. Biological Conservation, 141(11), 2832-2842. doi: 10.1016/j.biocon.2008.08.020.

Burger, J. (2000). Landscapes, tourism, and conservation. Science of the Total Environment, 249(1), 39-49. doi: 10.1016/S0048-9697(99)00509-4.

Burns, G. L., \& Howard, P. (2003). When wildlife tourism goes wrong: A case study of stakeholder and management issues regarding Dingoes on Fraser Island, Australia. Tourism Management, 24(6), 699712. doi: 10.1016/S0261-5177(03)00146-8.

Cooper, C., Larson, L., Dayer, A., Stedman, R., \& Decker, D. (2015). Are wildlife recreationists conservationists? 
Linking hunting, birdwatching, and pro-environmental behavior. The Journal of Wildlife Management, 79(3), 1-12. doi: 10.1002/jwmg.855.

Duffus, D. A., \& Dearden, P. (1990). Non-consumptive wildlife-oriented recreation: A conceptual framework. Biological Conservation, 53(3), 213-231. doi: 10.1016/0006-3207(90)90087-6.

Gao, J., Barbieri, C., \& Valdivia, C. (2014). Agricultural landscape preferences: Implications for agritourism development. Journal of Travel Research, 53(3), 366-379. doi: 10.1177/0047287513496471.

Gong, M. ., Ma, Y. ., Tian, M. Z., \& Chen, Y. . (2009). Tourism resource evaluation of the Hukou Waterfall National Geopark at the Yellow River. Acta Geoscientica Sinica, 30(3), 325-338.

Hamzah, F., \& Utomo, E. T. (2016). Implementasi sapta pesona pada museum mandala wangsit Kota Bandung. Jurnal Pariwisata, 3(2), 118-128. $\quad$ Retrieved from http://ejournal.bsi.ac.id/ejurnal/index.php/jp/article/view/1467.

Hauer, F. ., \& Lamberti, G. . (2011). Methods in Stream Ecology. Amsterdam: Academic Press.

Hudson, B. J. (1998). Waterfalls resources for tourism. Annals of Tourism Research, 25(4), 958-973. doi: 10.1016/S0160-7383(98)00043-7.

Hunter, C. (1997). Sustainable tourism as an adaptive paradigm. Annal of Tourism Research, 24(4), 850-867. doi: 10.1016/S0160-7383(97)00036-4.

Jaafar, M., \& Maideen, S. A. (2012). Ecotourism-related products and activities, and the economic sustainability of small and medium island chalets. Tourism Management, 33(3), 683-691. doi: 10.1016/j.tourman.2011.07.011.

Kementerian Pariwisata Republik Indonesia. (2016). Ranking Devisa Pariwisata terhadap 11 Ekspor Barang Terbesar, Tahun 2010-2014. Jakarta. Retrieved from www.kemenpar.go.id/userfiles/devisa20112015.pdf.

Kim, C. W., Scott, D., Thigpen, J. F., \& Kim, S. S. (1998). Economic impact of a birding festival. Festival Management \& Event Tourism, 5(1), 51-58. doi: 10.3727/106527098792186702.

Kizos, T., \& Iosifides, T. (2007). The contradictions of agrotourism development in Greece: Evidence from three case studies. South European Society and Politics, 12(1), 59-77. doi: 10.1080/13608740601155443.

Malkhanti, S. H. ., \& Routry, J. . (2011). Potential for agritourism development: Evedence from Sri Lanka. The Journal of Agricultural Sciences, 6(1), 45-58. doi: 10.4038/jas.v6i1.3812.

Postel, S., \& Richter, B. (2012). Rivers for Life: Managing Water for People and Nature. Washinton DC: Island Press.

Prasetyo, H. D., Hakim, L., \& Retnaningdyah, C. (2017). Evaluating environmental service of trisula waterfall as nature-based tourism attraction in Bromo Tengger Semeru National Park. Journal of Indonesian Tourism and Development Studies, 5(2), 101-106. doi: 10.21776/ub.jitode.2017.005.02.05.

Prideaux, B., \& Cooper, M. (2009). River Tourism. Cambridge: CABI Publishing.

Reynolds, P. C., \& Braithwaite, D. (2001). Towards a conceptual framework for wildlife tourism. Tourism Management, 22(1), 31-42. doi: 10.1016/S0261-5177(00)00018-2.

Ritchie, B. ., Burns, P., \& Palmer, C. (2005). Tourism Research Methods Integrating Theory with Practice. Cambridge: CABI Publishing.

Sharpley, R. (2002). Rural tourism and the challenge of tourism diversification: the case of Cyprus. Tourism Management, 23(3), 233-244. doi: 10.1016/S0261-5177(01)00078-4

Songa. (2016). Statistik Kunjungan Wisata Arung Jeram (Rafting). Probolinggo.

Steinbach, J. (1995). River related tourism in Europe: An overview. GeoJurnal, 35(4), 443-458. doi: $10.1007 / \mathrm{BF} 00824354$.

Stoeckl, N., Smith, A., Newsome, D., \& Lee, D. (2005). Regional economic dependence on iconic wildlife tourism: Case studies of Monkey Mia and Hervey Bay. The Journal of Tourism Studies, 16(1), 69-81. 
167 Pengembangan Potensi Ekowisata Sungai Pekalen Atas...

Retrieved

from

https://www.researchgate.net/publication/46156172_Regional_economic_dependence_on_iconic_wil dlife_tourism_Case_studies_of_Monkey_Mia_and_Hervey_Bay.

Trinca, D., Petroman, C., \& Țigan, V. (2011). The development of agrotourism potential in the hilly area of Arad County. Agro Buletin AGIR, 3(4), 287-294.

Whitten, T., Soeriaatmadja, R. E., \& Afiff, S. A. (1996). Ecology of Java \& Bali. Oxford: Oxford University Press.

Wicks, B. E., \& Merrett, C. D. (2003). Agritourism: An economic opportunity for Illinois agritourism. Rural Research Report, 14(9), 1-8.

Zhu, Y., Drake, S., Lü, H., \& Xia, J. (2010). Analysis of temporal and spatial differences in eco-environmental carrying capacity related to water in the Haihe River Basins, China. Water Resources Management, 24(6), 1089-1105. doi: 10.1007/s11269-009-9487-1. 